\title{
INTERFUEL: EPAct 2005 Section 701 Waiver and Compliance Process
}

\author{
Ron Stewart
}

June 2020

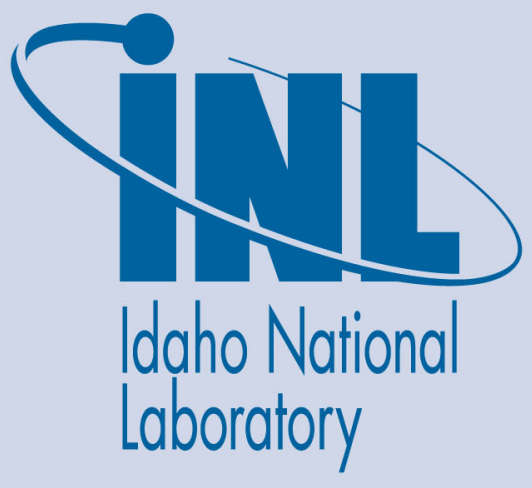

The INL is a U.S. Department of Energy National Laboratory operated by Battelle Energy Alliance 


\title{
INTERFUEL: EPAct 2005 Section 701 Waiver and Compliance Process
}

\author{
Ron Stewart \\ June 2020 \\ Idaho National Laboratory \\ Idaho Falls, Idaho 83415 \\ http://www.inl.gov \\ Prepared for the \\ U.S. Department of Energy \\ Office of Energy Efficiency and Renewable Energy \\ Under DOE Idaho Operations Office \\ Contract DE-AC07-05ID14517
}




\section{EPAct 2005 Section 701 Waiver and Compliance Process}

Process Changes \& Implications for FAST Reporting

INTERFUEL - June 10, 2020

Ron Stewart

FAST Support Team

Idaho National Laboratory

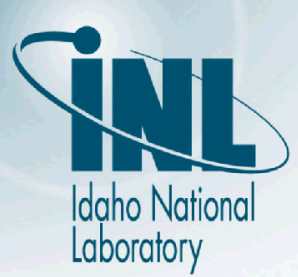

INL/MIS-20-58613:000 


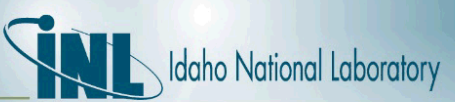

\section{Energy Policy Act 2005 Section 701}

- Requires relevant vehicles in EPAct-covered Federal agency fleets to consume alternative fuel when available

- Department of Energy (DOE) implemented process by which:

Agencies may request waivers for alt fuel vehicles without access to fuel

DOE reviews those waiver requests

- DOE evaluates agency compliance with EPAct's alt fuel consumption requirement

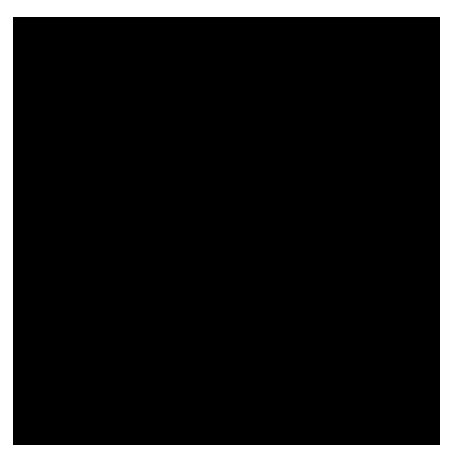




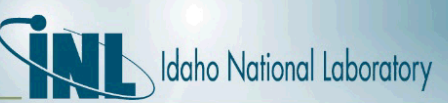

\section{Waiver Process: Recent History}

- Agencies submitted waiver requests through FAST during June data call Exemptions for the coming FY for vehicles w/o access to alt fuel

- Waivers based on fuel availability or cost

- Requests based on vehicle location, fuel type/configuration

- DOE's federal fleet program team reviewed waiver requests during July I August

Approved or rejected each group of waiver requests, based on

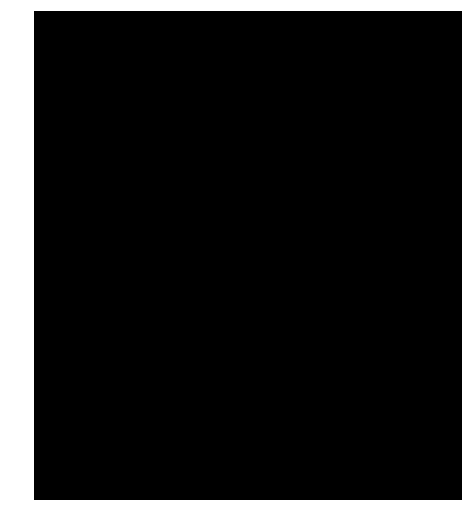

- Vehicle garage location

- Vehicle fuel type/configuration

- Fueling infrastructure location from DOE's Alt Fuel Data Center (AFDC)

Approved / rejected requests communicated to agencies in August / September

- Agencies used waivers to manage fuel consumption in compliance with EPAct requirement through year 


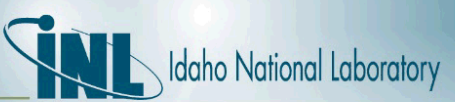

\section{Fleet Reporting: Recent History}

- FAST vehicle-level data reporting during October - December

Data element S-2, "EPAct 2005 Section 701 Designation"

- Agency indicated whether each vehicle, for prior year, was

- Exempt from the requirement for alt fuel consumption

- Had been granted a waiver from the requirement

- Was subject to the requirement (i.e., no waiver)

Provided two ways to look at how agencies were performing vs the requirement

- How closely did waiver requests align with reported 701 designations?

- For vehicles without waivers, did their fuel consumption show compliance?

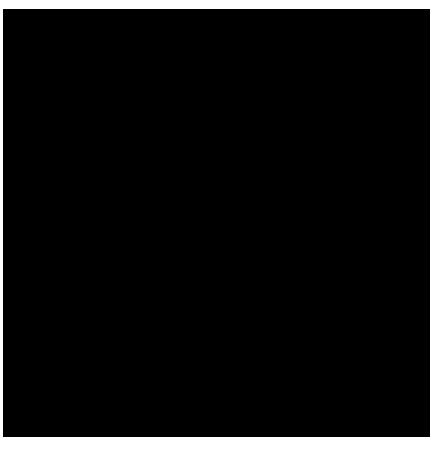




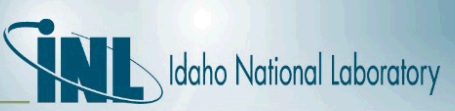

\section{Time Passes, Things Change}

- More agencies using DOE's FleetDASH system to review alt fuel consumption

More vehicles with transaction-level fueling data

Beginning 2017, FAST gets majority of (now all) fleet vehicles as vehicle-level data

- All fleet vehicles now reported with detailed location data

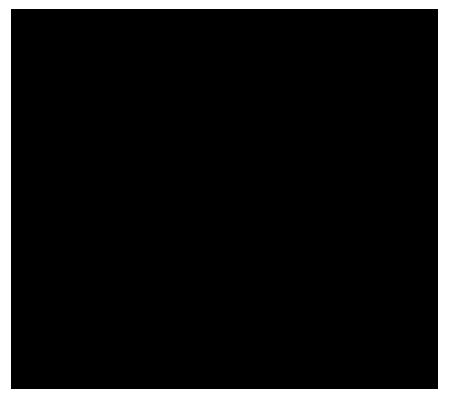




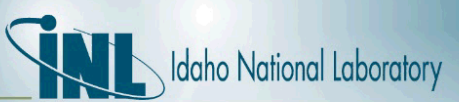

\section{Time Passes, Things Change}

Federal Fleet Team: Can we take advantage of these changes to get a better 701 process?

Simpler / less work for agencies?

- Take advantage of new data?

- Better characterization of compliance with EPAct's alt fuel consumption requirement?

\section{- Yes!}

- Conversations with agencies started several years ago

- Revamped process formally approved, guidance issued by DOE in March 2020

- Important changes to both FAST and FleetDASH 


\section{Changes to FAST Reporting}

- How do we accomplish this without breaking everything?

- Allow agencies to take advantage of revamped process

Transition to new process and provide time for agency systems and processes to change

\section{Re-purpose (gently!) existing data element S-2, "EPAct 2005 Section 701}

\section{Designation}

Change from designation of whether each vehicle was covered / waivered for past year...

... to designation of how agency wants vehicle to be treated for coming year

- Is the vehicle subject to the requirement?

- How should the vehicle be evaluated vs. the requirement?

- Does it need a waiver?

- If a waiver is needed, what is the basis for the waiver? 


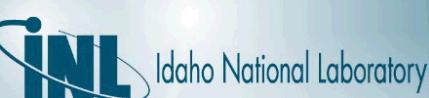

\section{Changes to FAST Reporting}

- Data element S-2, "EPAct 2005 Section 701 Designation"

New set of designations supported Fall 2020 for FY 2020 fleet data reporting:

- EXEMPT - Vehicle is exempt from EPAct alt fuel consumption requirement

- NO-WAIVER - Vehicle is subject to EPAct alt fuel consumption requirement and does not require a waiver (i.e., will consume only alt fuel)

- WREQ-DISTANCE - Vehicle is subject to requirement, but needs a waiver based on distance to alt fuel

- WREQ-NOACCESS - Vehicle is subject to requirement, but needs a waiver based on access restrictions to alt fuel

- WREQ-FUELCARD - Vehicle is subject to requirement, but needs a waiver based on lack of support for fleet fuel card(s) where alt fuel is available

- WREQ-COST - Vehicle is subject to requirement, but needs a waiver based on cost of alt fuel 


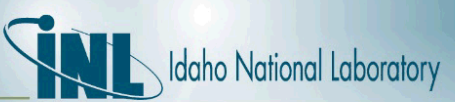

\section{Changes to FAST Reporting}

- Data element S-2, "EPAct 2005 Section 701 Designation"

New set of designations supported Fall 2020 for FY 2020 fleet data reporting:

- EXEMPT

- NO-WAIVER

- WREQ-DISTANCE

- WREQ-NOACCESS

- WREQ-FUELCARD

- WREQ-COST

- FLEETDASH - Vehicle is present in FleetDASH; FleetDASH will be used as basis for evaluating compliance

- DEFAULT (or not specified) - FAST and fleet team will use agency and vehicle attributes to determine designation 


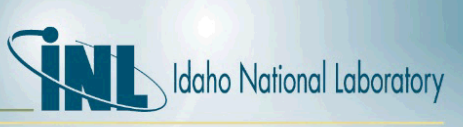

\section{Changes to FAST Reporting}

- Data element S-2, "EPAct 2005 Section 701 Designation"

Previous values for data element still supported

- Deprecated: still allowed but will be retired in the future

- Re-interpreted in manner that makes sense under new process:

$$
\text { Old EX = New EXEMPT }
$$

- Old COV = NeW NO-WAIVER

- Old WAIV = NeW WREQ-DISTANCE

Keeps existing systems and processes from breaking until they can be updated

- Updated validation rules

- Analogous to current rules for S-2

- Tuned for new designations

- Revised interpretations of older deprecated designations

- Ignore disposed vehicles 


\section{Till absumilumen}

\section{Changes to FAST Reporting}

- Data element S-2, "EPAct 2005 Section 701 Designation"

How does DEFAULT (or not specified) get interpreted?

- EXEMPT

Non-EPAct covered agency vehicles

Foreign vehicles

Disposed vehicles

LE / ER vehicles

Dedicated / single fuel configuration vehicles

- FLEETDASH

EPAct covered agency vehicles with dual / flex fuel configuration known to be in FleetDASH

\section{- NO-WAIVER}

All other vehicles (i.e., EPAct covered agency + domestic + non-LE / ER + dual / flex fuel configuration + not in FleetDASH)

DEFAULT is intentionally powerful!

- Agencies are encouraged to use it to streamline reporting 


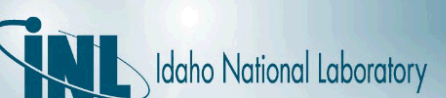

\section{What Happens After Reporting?}

- Vehicles in FleetDASH

Evaluated for compliance using FleetDASH and fuel transaction data

\section{- Vehicles not in FleetDASH}

Agency completes fall fleet data submission Information exported from FAST for fleet team to review waiver requests

Fleet team reviews and approves / rejects each waiver request

- Review result (approved / denied waiver) imported back into FAST for each vehicle

- Review result exposed through FAST query tool and communicated to agency POCs

- Agency compliance evaluated based on

- Coverage designations

- Approved / denied waiver requests

- Reported fuel consumption 


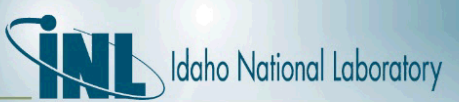

\section{FAST Program Points of Contact}

- DOE Federal Energy Management Program (FEMP)

Jay Wrobell

vrobell@ee.doe.gov

ndall Kam

kendall.kam@ee.doe.gov

GSA Office of Government-wide

Policy (OGP)

Jim Vogelsinger

James.vogelsinger@gsa.gov

trick McConnell

patrick.mcconnell@gsa.gov

EIA Office of Energy Consumption \& Efficiency Statistics

Cynthia Sirk

cynthia.sirk@eia.gov

$\square$

- INL FAST Support Team

Ron Stewart

ron.stewart@inl.gov 